\title{
Minimize Magnetic Field disorders by using Antioxidants
}

\author{
Sahar M. Awad \\ Physics department, Faculty of science, Al-Azhar university, Egypt.
}

\begin{abstract}
$\mathbf{T}$ HE study aimed to investigate the treatment effect of marjoram leaves on brain tissue and some biochemical properties that exposed to magnetic field (MF).Magnetic fields may cause heating of the skin and the tissue, which could lead to several disorders as increase the production of reactive oxygen species. Animals have the effective enzymatic antioxidant defensesystem including catalase (CAT), superoxide dismutase (SOD), and Glutathione (GSH) and Glutathione reductase (GSH-Px) enzymes. Lipid peroxidation in blood (erythrocytes) was measured as the amount of malondialdehyde (MDA). This system allow for scavenging of reactive oxygen species ROS and leading to protection of cells from oxidative damage. Fruits, plants and vegetables contain high amounts of antioxidants, like polyphenols, vitamin C, vitamin E, $\beta$-carotene, and lycopene.Plants as Marjoram contains several acids as urosolic acid, carnostic acid, and carnosol which used as free radical scavengers. So it protect organs as liver, brain and kidney and enhance the antioxidant activities .
\end{abstract}

Keyword : Brain, Magnetic field, Antioxidants, Marjoram .

\section{Introduction}

There are a number of several studies showing a possible link between exposure to magnetic fields in the home (and/or living close to high voltage power lines) and a small excess of childhood leukemia [1].It is estimated that 2 to 5 cases from the total of around 500 cases of childhood leukemia per year in the UK could be attributable to magnetic fields[1].

Exposure to most of environmental toxicants leads to formation of highly reactive compounds called free radicals. These radicals can be generated in the body as a reactive oxygen species (ROS). Most of the environmental toxicants are potential source of free radicals. These molecules are unstable since they have ion pair of electrons and leading to become highly reactive species. They easily react with cellular molecules such as proteins, lipids, carbohydrates and nucleic acids, and denature them. As a result of these reactions, those components lose their ability to function normally and ultimately resulting in various pathological conditions in living organisms [2].

Fruits, plants and vegetables contain high amounts of antioxidants, like polyphenols, vitamin $\mathrm{C}$, vitamin E, $\beta$-carotene, and lycopene [3]. The consumption of fruit juices, beverages and hot drinks was found to reduce the morbidity and mortality caused by degenerative diseases. Antioxidants are known to play a key role in the protective influence exerted by plants . Environmental pollution and technology are the main factors of brain damage. The excess of free radicals circulating in the body oxidize the low density lipoproteins (LDL), and making them potentially lethal .They can also accelerate aging processes and have been linked to other very serious pathologies, such as brain stroke, diabetes mellitus, rheumatoid arthritis, Parkinson's disease, Alzheimer's disease and cancer. Recently, scientists are interested in using natural antioxidants in medicinal plants and herbs to treat these disorders.[4].

Marjoram is a medicinal herb, used as home remedy for treatment of different disorders [5]. Marjoram contains urosolic acid, carnostic acid, and carnosol which used as free radical scavengers. So it may protect liver, brain and kidney [6].

This study aimed to investigate the effect of marjoram on brain tissue and some biochemical properties that exposed to magnetic field . 


\section{Materials and Methods}

\section{Materials}

Marjoram dry leaves were purchased from local market of Egypt. The experiment was formed upon rats weighting $180-200 \mathrm{~g}$. All animals were maintained under standard condition of humidity,temperature, and light (12: 12 dark : light cycle ).

Experiments include 4 group of 10 rat each , group (a) is a normal group, group (b) is the group exposed to magnetic field strength 15 Gauss for 4 hours, group (c) is the group fed on chow diet mixed with $10 \%$ marjoram leaf for 1 week after exposure to 15 gauss MF for $4 \mathrm{H}$, and group (d) is the group fed on chow diet mixed with 10 $\%$ marjoram leaf for 1 week before exposure to 15 gauss MF for $4 \mathrm{H}$. The homogeneous magnetic field generator is consisted of coil placed on a wooden rack. The coil consists of 320 turns from electrically insulated $2 \mathrm{~mm}$ copper wire thickness and is wounded in a homogenous way around a copper cylinder of $2 \mathrm{~mm}$ thick, $50 \mathrm{~cm}$ diameter and $60 \mathrm{~cm}$ length. The ends of the coil are connected to variacthat fed from the mains $(\approx 220 \mathrm{~V}$ and $50 \mathrm{~Hz})$ to produce different alternating magnetic fields. The magnetic field strength inside magnetic chamber (where the animal housed) is adjusted by changing the voltage across the coil to generate magnetic field of $1.5 \mathrm{mT}$ in the area where the animals housed[7].

\section{Methods}

A- Biochemical analysis: Blood samples were collected from the jugular vein in all ratsin heparinized tube to obtain plasma. Blood tubes were centrifuged at $3000 \mathrm{rpm}$ for $10 \mathrm{~min}$ and supernatant was removed. Plasma was kept frozen.Analytical Procedures: Lipid peroxidation in blood (erythrocytes) was measured as the amount of malondialdehyde (MDA) formed employing thiobarbituric acid as described by Stocks and Dormandy[8] by using UVVisible spectrophotometer, Shimadzu. Catalase (CAT), superoxide dismutase (SOD), and Glutathione (GSH) and Glutathione reductase (GSH-Px) enzymesactivities were quantitated spectrophotometrically according to Mariami $[9,10]$ respectively.

B- Histopathological examination : samples from brain were collected from all groups, fixed in $10 \%$ formalin. Washing was done in tap water then serial dilutions of alcohol (methyl, ethyl and absolute ethyl )were used for dehydration . Specimens were cleared in xylene and embedded in paraffin at 56 degree in hot air oven for twenty four hours . Paraffin bees wax tissue blocks were prepared for sectioning at 4 microns thickness by slidgemicrotome. The obtained tissue sections were collected on glass slides ,deparaffinized, stained by hematoxylinand eosin stain for examination through the light electric microscope [11].

\section{Results and Discussions}

\section{A-Biochemical results}

Levels of SOD, CAT, GSH, and GSHPX decreased in group (b), these referred to occurrence of oxidative stress .Oxidative stress cause dangerous production of reactive species resulting intissue damage [12]. MDA increased in exposed group (b) compared to normal one as shown in table (1). Group (c) which feed on Marjoram after exposure to MF showed a normal values of SOD, CAT, GSH, GSH-PX and MDA. Marjoram lowered the hazards effect of MF on blood antioxidants. Feeding Marjoram before MF exposure in group (d) has no improve effect on antioxidant parameters.

TABLE 1. Antioxidant parameters of Normal group (a), Group (b)which exposed to MF, Group (c) feeding marjoram after exposure to MF, Group (d) feeding Marjoram before exposure to MF .

\begin{tabular}{lccccc}
\hline & $\begin{array}{c}\text { SOD } \\
\boldsymbol{\mu ~ m o l} / \mathbf{m l}\end{array}$ & $\begin{array}{c}\mathbf{C A T} \\
\boldsymbol{\mu ~ m o l} / \mathbf{m l}\end{array}$ & $\begin{array}{c}\text { GSH-PX } \\
\boldsymbol{\mu ~ m o l} / \mathbf{m l}\end{array}$ & $\begin{array}{c}\text { GSH } \\
\mathbf{~ m g} / \mathbf{d l}\end{array}$ & $\begin{array}{c}\text { MDA } \\
\mathbf{n ~ m o l} / \mathbf{m l}\end{array}$ \\
\hline Group (a) & $309.4 \pm 9.36$ & $139.4 \pm 1.11$ & $169.4 \pm 1.24$ & $40.16 \pm 0.24$ & $33.52 \pm 0.51$ \\
Group (b) & $161.51 \pm 8.11$ & $89.5 \pm 0.15$ & $126.5 \pm 1.56$ & $21.06 \pm 1.16$ & $43.13 \pm 0.21$ \\
Group (c) & $298.3 \pm 8.21$ & $141.3 \pm 2.21$ & $159.2 \pm 1.03$ & $42.23 \pm 0.21$ & $32.91 \pm 0.13$ \\
Group (d) & $180.3 \pm 6.43$ & $83.2 \pm 1.04$ & $119.3 \pm 0.91$ & $23.24 \pm 0.39$ & $41.09 \pm 0.43$ \\
\hline
\end{tabular}

Egypt. J. Biophys. Biomed. Eng., Vol. 20 (2019) 


\section{B- Histopathological Results}

\section{Hippocampus - subiculum}

There was no histopathological alteration and the normal histological structure of the neurons were recorded in (Fig.1a , c). Nuclear pyknosis and degeneration were observed in the neurons (Fig.1b,d).

\section{Hippocampus - Fascia dentata and hilus}

The normal histological structure of the neurons were recorded in (Fig.2a, c). The neurons showed nuclear pyknosis and degeneration as recorded in (Fig.2b, d)
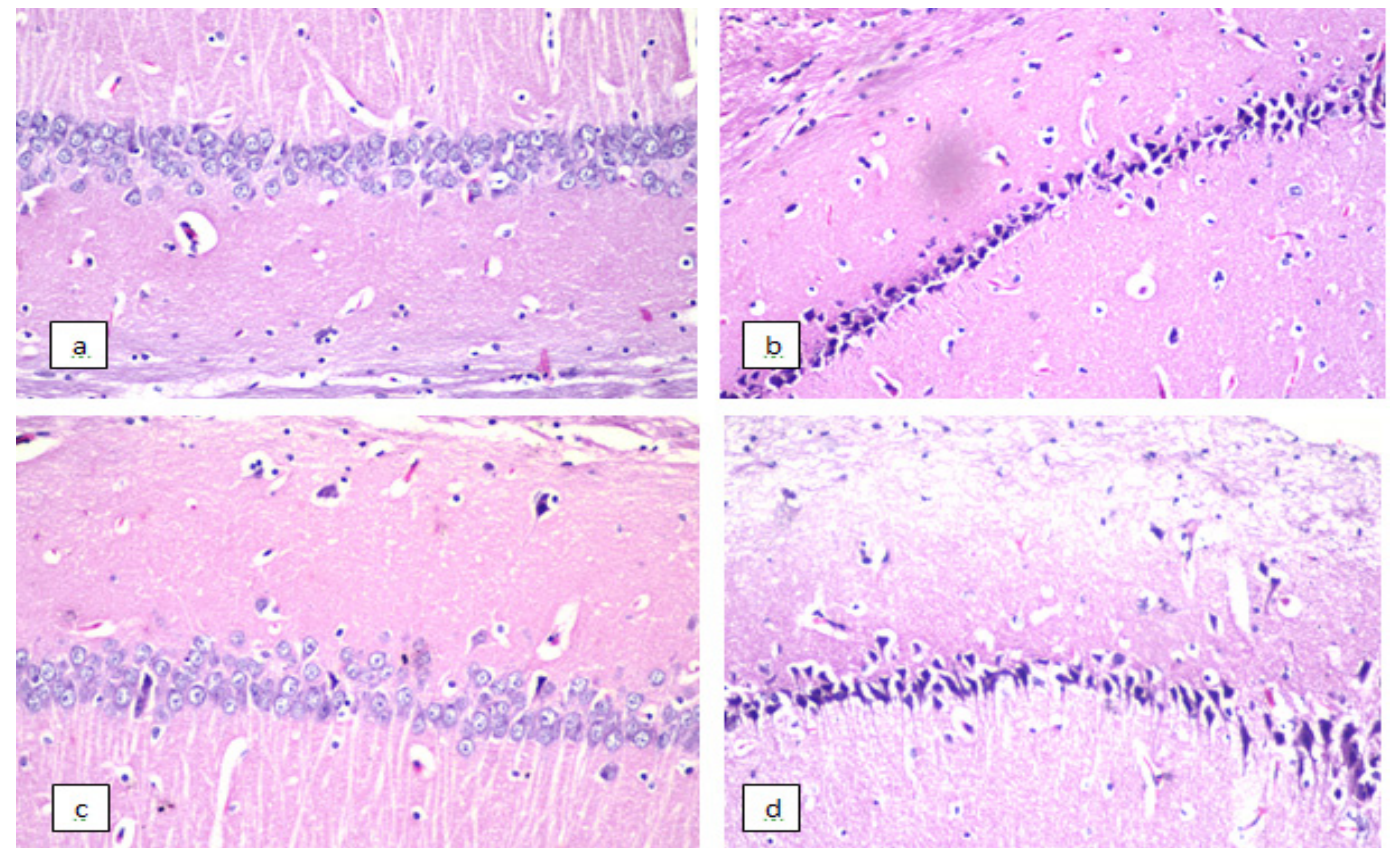

Fig.1. Subiculum in hippocampus of rat for a)Normal group, b)exposed group to MF, c)exposed group to MF then treated with marjoram, d)protected group with marjoram then exposed to MF .
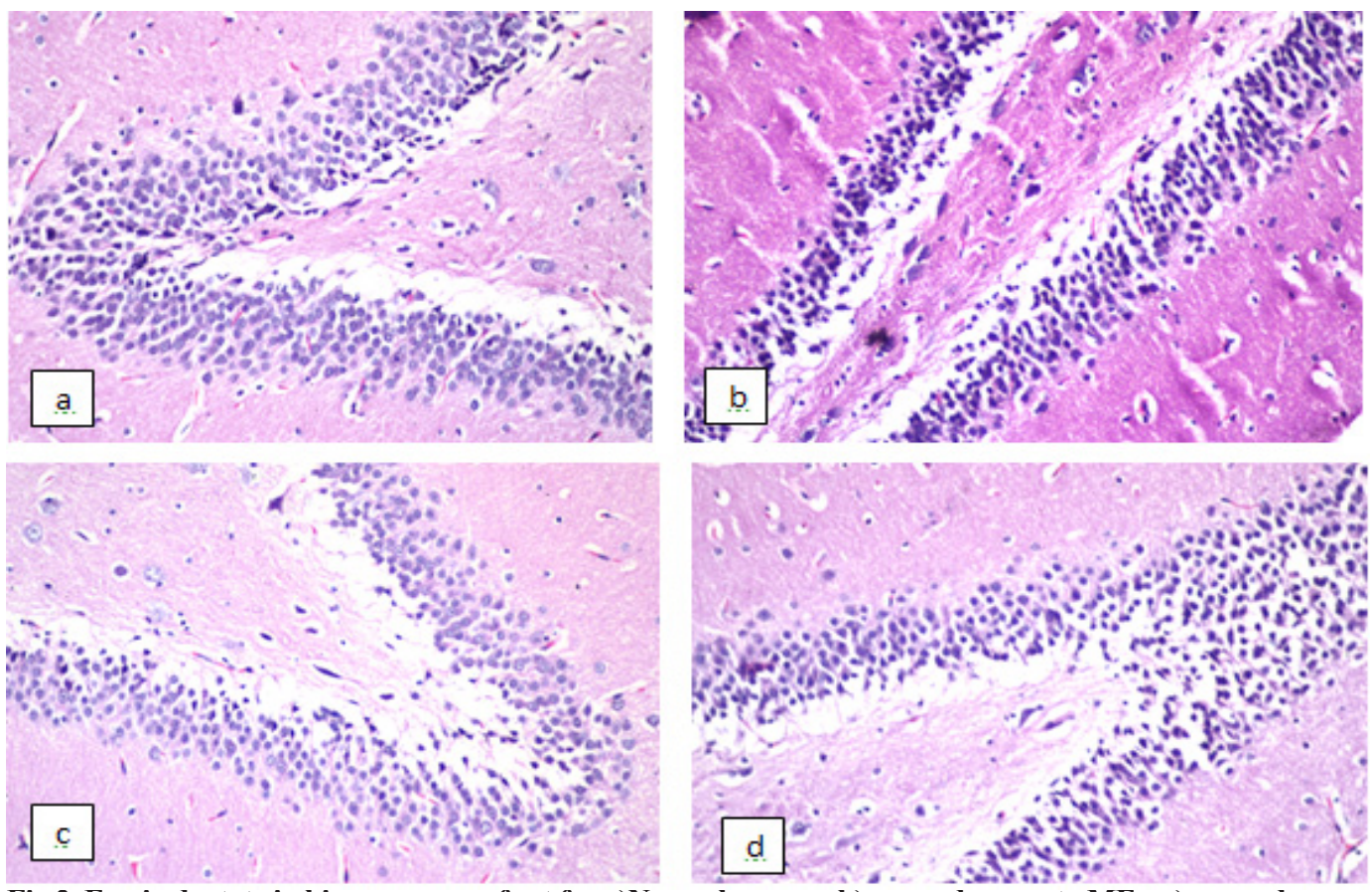

Fig.2. Fascia dentate in hippocampus of rat for a)Normal group, b)exposed group to MF, c)exposed group to MF then treated with marjoram, d)protected group with marjoram then exposed to MF . 


\section{Striatum}

There was no histopathological alteration and the normal histological structure of the neurons were recorded in (Fig.3a.c). Most of the neurons
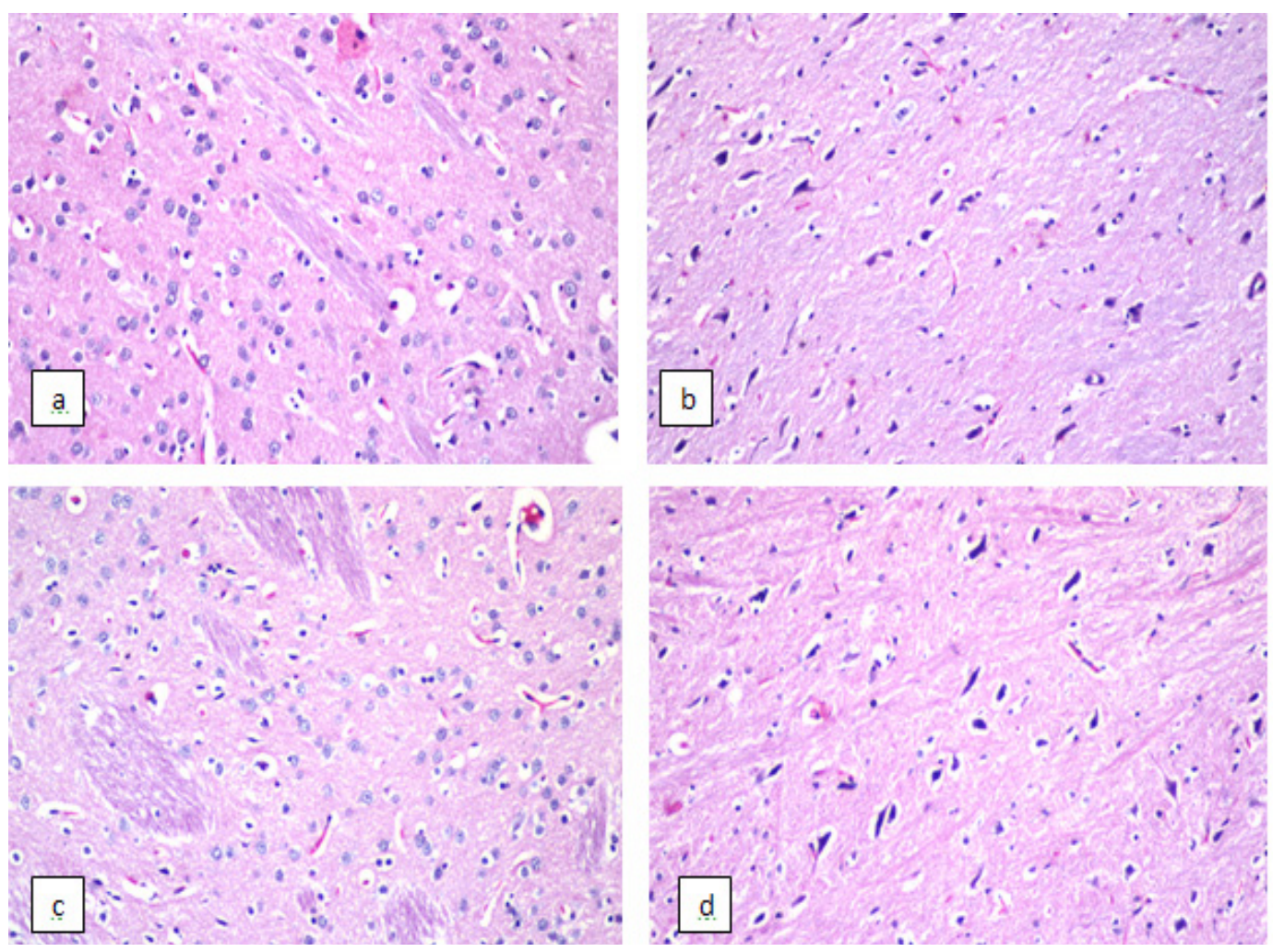

Fig.3. Striatum of rat's brain for a)Normal group, b)exposed group to MF, c)exposed group to MF then treated with marjoram, d)protected group with marjoram then exposed to MF . showed nuclear pyknosis and degeneration associated with gliosis in between (Fig.3b , d), as well as focal multiple eosinophilic plagues formation . 
5. Naglaa, H.M. Hassanen (2012) Hepatoprotective effect of Marjoram on oxidative stress against carbon tetrachloride- induced toxicity in rats , Egyptian journal of nutrition and health;7 : 6985 .

6. Naifobaid Al-Harbi (2011) Effect of Marjoram extract treatment on the cytological and biochemical changes induced by cyclophosphamide in mice , journal of medicinal plants research 5;5479-5485.

7. Aziza A. El Saeid and Mona A. Mohamed (2016) Effects of Whole Body Exposure to Extremely Low Frequency Magnetic Field (ELFMF) on Physical and Biological Parameters in vivo Rats , International Journal of Environment; 5 : 1-8.

8. Stocks, J. and T.L. Dormandy (1971) Autoxidation of red cell lipid induced by hydrogen peroxide,Br.J.Hematol. ; 20: 95-111.

9. Mariami, M. and H. Yoshikawa (1979) A simplified assay method of superoxide dismutase, Clinica ChimicaActa ; 92: 337-342.

10. Johansson, L.H. and L.A.H. Borg (1988) A spectrophotometric method for determination of catalase activity in small tissue sample, Anal. Biochem. ; 174, 331-336.

11. Banchroft, J.D.; Stevens, A. And Turner, D.R. (1996) Theory and practice of histological techniques, Fourth Ed. Churchil Livingstone, New York, London, San Francisco, Tokyo.

12. A.H.Hashish, M.A.El-Missiry, H.I.Abdelkader, and R.H.Abou-Saleh (2008) Assessment of biological changes of continuous whole body exposure to static magnetic field and extremely low frequency electromagnetic fields in mice, Ecotoxicology and environmental safety ;895902.

13. AkkusI (1995) Free radicals and their pathophysiological effects.ISBN 975-543-038-5. Konya, Turkey: Mimoza Press.

(Recieved 7/9/2019;

accepted 8/10/2019) 


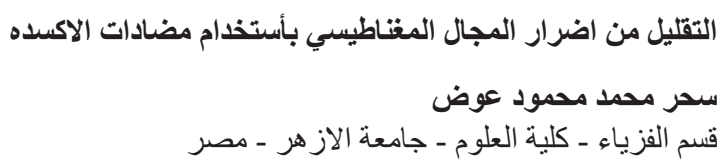

تهدف الدراسة إلى دراسة تأثثر علاج أوراق البردقوش على أنسجة المخ وبعض الخواص الكيميائية الحيوية

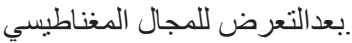

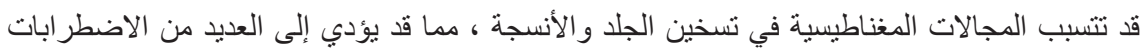



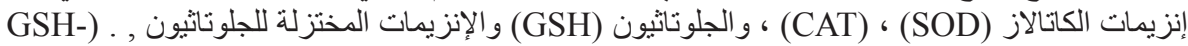



تسمح مضادات الاكسده بتطهير أنواع الأكسجين التفاعلية ROS وتؤدي إلى حماية الخلايا من التآكل

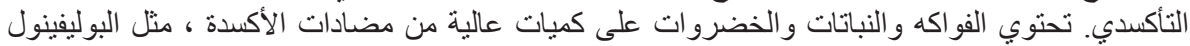



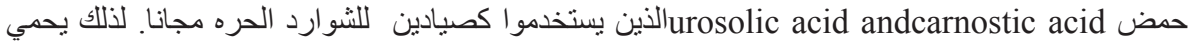
الأعضاء كالكبد و الدماغ و الكلى ويعزز أنشطة مضادات الأكسدة. 